\title{
Structural Insights into Retinal Guanylate Cyclase Activator Proteins (GCAPs)
}

\author{
James B. Ames
}

Citation: Ames, J.B. Structural Insights into Retinal Guanylate Cyclase Activator Proteins (GCAPs). Int. J. Mol. Sci. 2021, 22, 8731 .

https://doi.org/10.3390/ijms22168731

Academic Editors: Pere Garriga and Daniele Dell'Orco

Received: 21 July 2021

Accepted: 10 August 2021

Published: 13 August 2021

Publisher's Note: MDPI stays neutral with regard to jurisdictional claims in published maps and institutional affiliations.

Copyright: (c) 2021 by the author Licensee MDPI, Basel, Switzerland. This article is an open access article distributed under the terms and conditions of the Creative Commons Attribution (CC BY) license (https:// creativecommons.org/licenses/by/ $4.0 /)$.
Department of Chemistry, University of California, Davis, CA 95616, USA; jbames@ucdavis.edu; Tel.: +1-1530-752-6358

Abstract: Retinal guanylate cyclases (RetGCs) promote the $\mathrm{Ca}^{2+}$-dependent synthesis of cGMP that coordinates the recovery phase of visual phototransduction in retinal rods and cones. The $\mathrm{Ca}^{2+}$-sensitive activation of RetGCs is controlled by a family of photoreceptor $\mathrm{Ca}^{2+}$ binding proteins known as guanylate cyclase activator proteins (GCAPs). The $\mathrm{Mg}^{2+}$-bound $/ \mathrm{Ca}^{2+}$-free GCAPs bind to RetGCs and activate cGMP synthesis (cyclase activity) at low cytosolic $\mathrm{Ca}^{2+}$ levels in light-activated photoreceptors. By contrast, $\mathrm{Ca}^{2+}$-bound GCAPs bind to RetGCs and inactivate cyclase activity at high cytosolic $\mathrm{Ca}^{2+}$ levels found in dark-adapted photoreceptors. Mutations in both RetGCs and GCAPs that disrupt the $\mathrm{Ca}^{2+}$-dependent cyclase activity are genetically linked to various retinal diseases known as cone-rod dystrophies. In this review, I will provide an overview of the known atomic-level structures of various GCAP proteins to understand how protein dimerization and $\mathrm{Ca}^{2+}$ dependent conformational changes in GCAPs control the cyclase activity of RetGCs. This review will also summarize recent structural studies on a GCAP homolog from zebrafish (GCAP5) that binds to $\mathrm{Fe}^{2+}$ and may serve as a $\mathrm{Fe}^{2+}$ sensor in photoreceptors. The GCAP structures reveal an exposed hydrophobic surface that controls both GCAP1 dimerization and RetGC binding. This exposed site could be targeted by therapeutics designed to inhibit the GCAP1 disease mutants, which may serve to mitigate the onset of retinal cone-rod dystrophies.

Keywords: phototransduction; retinal guanylate cyclase; calcium; GCAP1; GCAP2; GCAP5

\section{Introduction}

\section{1. $\mathrm{Ca}^{2+}$-Sensitive Regulation of RetGC Coordinates Visual Recovery}

Visual excitation of retinal rod and cone photoreceptors is triggered by a phototransduction cascade in which light excitation activates a photoreceptor-specific phosphodiesterase that in turn hydrolyzes cGMP (see reviews by [1,2]). The light-induced lowering of cGMP levels in photoreceptor cells causes the closure of cGMP-gated cation channels in the plasma membrane, resulting in membrane hyperpolarization (see reviews by [3,4]). The light-induced membrane hyperpolarization rapidly recovers back to the resting potential of the dark state when the light stimulus is removed in a process known as visual recovery. The recovery phase of phototransduction involves replenishing the photoreceptor cGMP levels [5] by the $\mathrm{Ca}^{2+}$ sensitive activation [6,7] of retina-specific guanylate cyclases (RetGCs) [8,9]. The $\mathrm{Ca}^{2+}$-dependent activity of RetGC is controlled by intracellular domains $[10,11]$ that interact with soluble EF-hand $\mathrm{Ca}^{2+}$ sensor proteins, called guanylate cyclase activator proteins (GCAP1-5, see Figure 1) [8,12-16].

Light-induced closure of cGMP-gated channels in vertebrate rod and cone photoreceptors causes a 10 -fold decrease in the cytosolic free $\mathrm{Ca}^{2+}$ concentration $[17,18]$. RetGC catalysis is activated by $\mathrm{Ca}^{2+}$-free GCAPs in light-activated photoreceptors $[8,12,13,19,20]$, whereas the cyclase activity is inhibited by $\mathrm{Ca}^{2+}$-bound GCAPs in dark-adapted photoreceptors $[5,19,21]$. During visual recovery, a photoreceptor cell exhibits a more than 10 -fold increase in cGMP production due to the $\mathrm{Ca}^{2+}$-sensitive activation of RetGC by GCAPs $[5,22]$ and is a critical step for controlling the recovery rate of a single-photon response [4,5] as well as the cone response to stronger light stimuli [23]. 


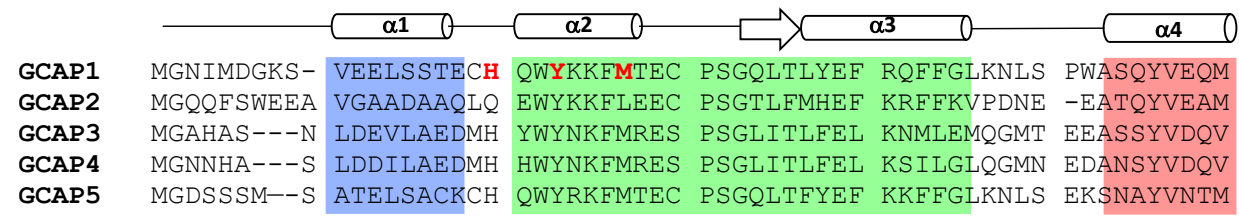

\begin{tabular}{|c|c|c|c|c|c|}
\hline$\alpha 40$ & $\alpha 5$ & 0 & $\alpha 6$ & & $\alpha 7$ \\
\hline FETE & YVAA & SI & $\mathrm{Y}$ & IGCIDB & $\mathrm{DE}$ \\
\hline $\mathrm{FP}$ & $\mathrm{TI}$ & & & NGCIDR & \\
\hline FFTE & EYI & VSLI & $\mathrm{E}$ & $\mathrm{R}$ & DEMET \\
\hline FCTFD & YIDFVEYIAA & ISLI & QKI & NGKIDK & DELET \\
\hline FKTFDIDDDG & MEYVI & LSL & RLRYFKLF & MDGSGCID & DELLLIFKAV \\
\hline
\end{tabular}
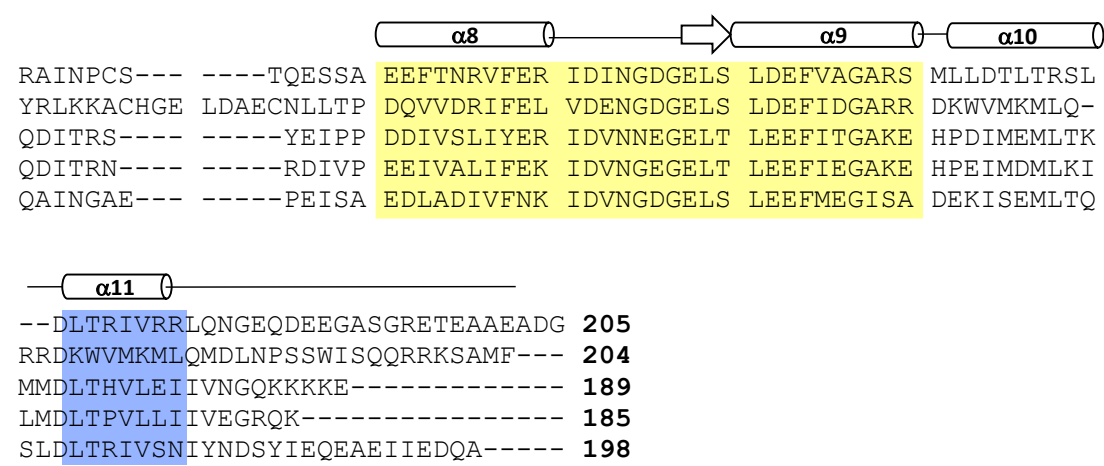

Figure 1. Amino acid sequence alignment of GCAP proteins (bovine GCAP1-2 and zebrafish GCAP3-5). Secondary structure elements (helices and strands) are depicted by cylinders and arrows. EF-hand residues are shaded in green, red, cyan, and yellow. The terminal residues that contact the myristoyl group are shaded purple. Exposed hydrophobic residues at the GCAP1 dimerization site are highlighted in bold and red.

\section{2. $\mathrm{Ca}^{2+} / \mathrm{Mg}^{2+}$ Binding to GCAPs Control Activation of RetGC}

GCAP proteins bind to and activate RetGC in light-activated photoreceptors that contain low $\mathrm{Ca}^{2+}$ levels (less than $50 \mathrm{nM}$ ) and physiological $\mathrm{Mg}^{2+}$ levels (1 mM) [24-27]. Thus, GCAP proteins that exist in light-activated photoreceptors activate RetGC and are called the activator state. At least one $\mathrm{Mg}^{2+}$ binds to GCAP1 in the activator state [26], and NMR studies reveal that $\mathrm{Mg}^{2+}$ is bound to GCAP1 at the second EF-hand (EF2 in Figure 1) [28]. The apo-state of GCAP1 $\left(\mathrm{Ca}^{2+}\right.$-free $/ \mathrm{Mg}^{2+}$-free) contains a regular secondary structure [29] but does not adopt a stable three-dimensional fold $[25,28]$. The $\mathrm{Ca}^{2+}$-free $/ \mathrm{Mg}^{2+}$-free GCAPs form a flexible molten-globule state, which could explain why GCAPs do not activate RetGC in the absence of $\mathrm{Mg}^{2+}$ [24]. Thus, $\mathrm{Mg}^{2+}$ binding to GCAP1 is required to stabilize its protein structure to promote activation of RetGC $[8,25,30]$. By contrast, $\mathrm{Ca}^{2+}$ binding to GCAP1 (in place of $\mathrm{Mg}^{2+}$ binding) stabilizes a distinct structure important for the inhibition of RetGC [21]. $\mathrm{Ca}^{2+}$ binds to GCAPs at the second, third, and fourth EF-hands (EF2, EF3, and EF4 in Figure 1) [31,32]. The apparent dissociation constant for $\mathrm{Ca}^{2+}$ binding to GCAPs is $100 \mathrm{nM}[24,28]$, whereas $\mathrm{Mg}^{2+}$ binds to GCAPs in the micromolar range $[25,27,28]$. Dark-adapted rod cells have relatively high cytosolic $\mathrm{Ca}^{2+}$ levels $\left(\left[\mathrm{Ca}^{2+}\right]_{\text {free }}=250-500 \mathrm{nM}\right.$ [18], which implies that GCAPs are nearly saturated with $\mathrm{Ca}^{2+}$ in dark-adapted rod cells. Light-activation of the rod cell causes a dramatic lowering of the cytosolic $\mathrm{Ca}^{2+}$ level $\left(\left[\mathrm{Ca}^{2+}\right]_{\text {free }}=5-50 \mathrm{nM}[17,18,33]\right)$ while the $\mathrm{Mg}^{2+}$ level remains fixed at $\left[\mathrm{Mg}^{2+}\right]_{\text {free }} \sim 1 \mathrm{mM}$ [34]. Therefore, in light-adapted rods, GCAPs are bound to $\mathrm{Mg}^{2+}$ instead of $\mathrm{Ca}^{2+}$. In essence, the $\mathrm{Mg}^{2+}$-bound $/ \mathrm{Ca}^{2+}$-free GCAPs in light-activated photoreceptors turn on the synthesis of cGMP to help restore the dark-adapted photoreceptor during visual recovery $[8,12,13]$, whereas $\mathrm{Ca}^{2+}$-saturated GCAPs turn off the synthesis of cGMP in the resting dark state $[19,21]$. 


\subsection{Mutations in GCAP1 Cause Retinal Disease}

Mutations in GCAP1 that weaken or disable $\mathrm{Ca}^{2+}$ binding to the EF-hands cause GCAP1 to constitutively activate RetGC in rod and cones. Some of these mutations (Y99C, D100G, E111V, and E155G) are genetically linked to retinal diseases known as cone-rod dystrophies [29,35,36]. For example, the GCAP1 mutants (Y99C [21,37], D100G [38], E111V [39] and E155G $[40,41]$ ) each prevent $\mathrm{Ca}^{2+}$ binding to EF3 or EF4 under physiological conditions, which enables the $\mathrm{Ca}^{2+}$-free $/ \mathrm{Mg}^{2+}$-bound GCAP1 activator state to persist in both light-activated and dark-adapted photoreceptors. In essence, these constitutively active GCAP1 mutants fail to turn off the cyclase activity in dark-adapted photoreceptors and cause persistent activation of RetGC [42,43]. This constitutive activation of RetGC causes elevated cGMP levels in photoreceptor cells that promote apoptosis and disease [42,44,45]. Future studies are needed to discover therapeutic agents that bind specifically to the constitutively active mutants of GCAP1 (Y99C, D100G, E111V, and E155G) to block or prevent their constitutive activation of RetGCs, which may diminish or slow down the onset of cone-rod dystrophies.

\section{Results and Discussion}

\subsection{Structural Architecture of GCAPS}

Mammalian photoreceptors have two different GCAP isoforms (GCAP1 and GCAP2 in Figure 1) that are more than 65\% identical to GCAP homologs found in zebrafish photoreceptors (GCAP3-5 in Figure 1). All of the GCAPs contain 200 residues, 4 EF-hand motifs (highlighted in color in Figure 1), a myristoyl group covalently attached to the $\mathrm{N}$-terminal glycine, and non-conserved residues at the $\mathrm{N}$ - and C-termini $(\alpha 1$ and $\alpha 11$ in Figure 1). The second, third, and fourth EF-hands each bind to $\mathrm{Ca}^{2+}$ or $\mathrm{Mg}^{2+}$ as described above. The first EF-hand (EF1) does not bind to $\mathrm{Ca}^{2+} \mathrm{Or} \mathrm{Mg}^{2+}$ because of unfavorable residues in the EF-hand binding loop (Cys29 in GCAP1 or Arg25 in GCAP3, see Figure 1). The lack of metal binding to the first EF-hand allows it to adopt an unusual structure that interacts with the N-terminal myristoyl group [32,46,47]. Outside of the core EFhand region, the non-conserved helices ( $\alpha 1$ and $\alpha 11$, highlighted purple in Figure 1 ) both form contacts with the myristoyl group [32]. Atomic-level structures are known for $\mathrm{Ca}^{2+}$ bound forms of GCAP1 [32] and GCAP2 [31], and $\mathrm{Mg}^{2+}$-bound $/ \mathrm{Ca}^{2+}$-free GCAP1 [48] as described below.

\subsubsection{NMR Structure of GCAP2}

The NMR structure of the $\mathrm{Ca}^{2+}$-saturated and unmyristoylated GCAP2 (Figure 2A) was the first atomic-resolution structure of a GCAP protein [31]. The first 20 amino acids from the $\mathrm{N}$-terminus and the last 19 residues from the $\mathrm{C}$-terminus in unmyristoylated GCAP2 could not be resolved by NMR (see dotted lines in Figure 2A). The core region of GCAP2 (residues 23-185) contains 4 EF-hands that are structurally similar to the EFhands in $\mathrm{Ca}^{2+}$-bound recoverin $[49,50]$. An important structural difference is that $\mathrm{Ca}^{2+}$ is bound at EF2, EF3, and EF4 in GCAP2, in contrast to recoverin where $\mathrm{Ca}^{2+}$ is bound only at EF2 and EF3 [51]. The lack of N-terminal myristoylation in the NMR structure of GCAP2 may contribute to the structural disorder at the N- and C-termini (dotted lines in Figure 2A). This could account for why the N-terminal myristoyl group in GCAP2 is exposed to the exterior in the presence of lipid bilayer membranes [52,53], which could enable the myristoyl group to anchor GCAP2 to membranes $[54,55]$. The exposed and unstructured N-terminal region in the GCAP2 NMR structure may explain why GCAP2 can exhibit $\mathrm{Ca}^{2+}$-dependent membrane binding, whereas GCAP1 does not [56]. 
A

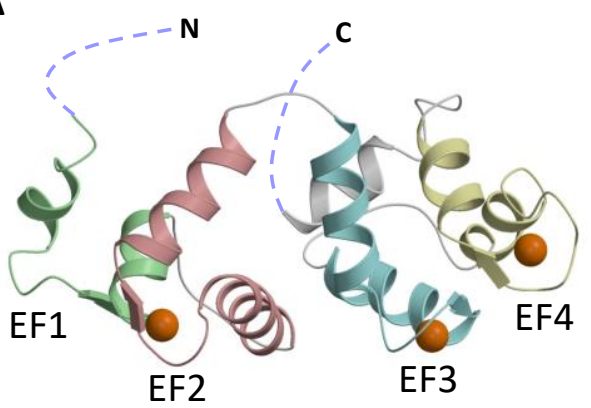

C

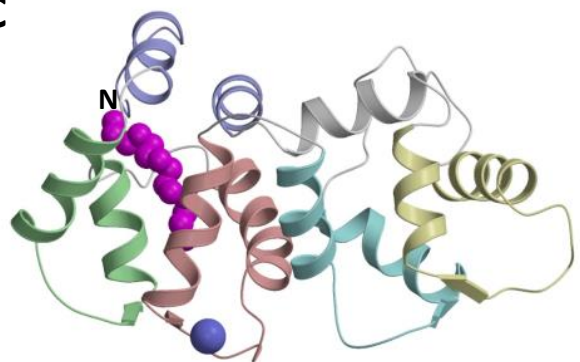

B

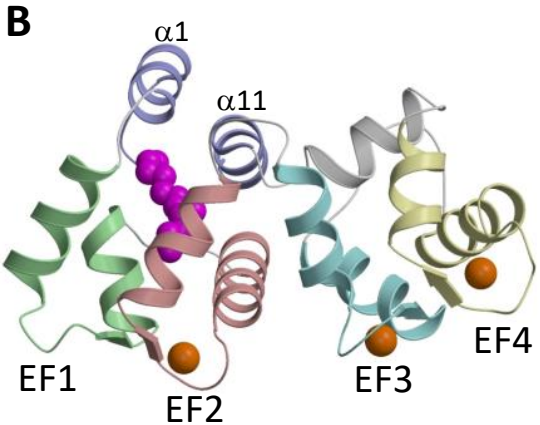

D

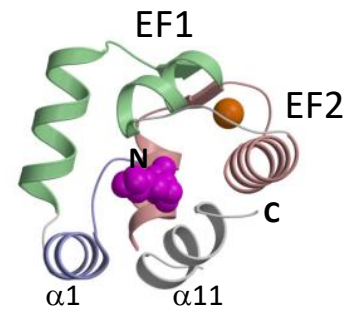

Figure 2. Atomic-level structures of unmyristoylated GCAP2 (A), myristoylated GCAP1 (B), $\mathrm{Mg}^{2+}$ bound GCAP1 ${ }^{\mathrm{V} 77 \mathrm{E}}(\mathrm{C})$, and myristoyl group binding site in $\mathrm{Ca}^{2+}$-bound GCAP1 (D). The color scheme is the same as in Figure 1. The EF-hands are shaded green, red, cyan, and yellow. The terminal helices ( $\alpha 1$ and $\alpha 11$ ) that contact the myristoyl group are colored purple. Bound $\mathrm{Mg}^{2+}$ and $\mathrm{Ca}^{2+}$ are colored purple and orange, respectively. The N-terminal myristoyl group is colored magenta.

\subsubsection{Crystal Structure of GCAP1}

The x-ray crystal structure of myristoylated GCAP1 (Figure 2B) showed the N-terminal myristoyl group to be sequestered inside the protein [32]. The four EF-hands in GCAP1 (Figures 1 and 2B) are grouped into two globular domains: the $\mathrm{N}$-domain is comprised of EF1 and EF2 and the C-domain is comprised of EF3 and EF4. $\mathrm{Ca}^{2+}$ is bound to GCAP1 at EF2, EF3, and EF4, and the structure of each $\mathrm{Ca}^{2+}$-bound EF-hand in GCAP1 (Figure 2B) adopts the familiar open conformation as seen in calmodulin and other $\mathrm{Ca}^{2+}$-bound EFhand proteins [57]. Indeed, the interhelical angles for each $\mathrm{Ca}^{2+}$-bound EF-hand in GCAP1 are nearly identical to those of GCAP2 (Figure 2A). A unique structural feature of GCAP1 is that the N-terminal $\alpha$-helix ( $\alpha 1$ in Figure 1 ) and C-terminal helix $(\alpha 11)$ are held closely together by their mutual interaction with the N-terminal myristoyl group (Figure 2D). Thus, the covalently attached myristoyl group in GCAP1 is sequestered within a unique environment inside the $\mathrm{Ca}^{2+}$-bound protein and prevents GCAP1 from having a $\mathrm{Ca}^{2+}$-myristoyl switch $[28,56]$. In essence, the myristoyl group serves to bridge both the N-terminal and C-terminal ends of the protein, which explains how $\mathrm{Ca}^{2+}$-induced conformational changes in the C-terminal domain (particularly in EF4) might be transmitted to a possible target binding site in EF1. A Ca ${ }^{2+}$-myristoyl tug mechanism $[58,59]$ has been proposed to explain how $\mathrm{Ca}^{2+}$-induced conformational changes in EF4 serve to "tug" on the adjacent C-terminal helix that connects structurally to the myristoyl group and EF1. This tug mechanism helps explain how $\mathrm{Ca}^{2+}$-induced structural changes in EF4 might be relayed to the cyclase binding region in EF1 [60]. The $\mathrm{Ca}^{2+}$-induced structural changes involving the C-terminal helix might also be related to $\mathrm{Ca}^{2+}$-dependent phosphorylation of S201 in GCAP2 [25].

\subsection{3. $\mathrm{Ca}^{2+}$-Induced Conformational Changes in GCAP1}

The atomic-level structure of $\mathrm{Ca}^{2+}$-free $/ \mathrm{Mg}^{2+}$-bound activator form of wild-type GCAPs is currently not known. A GCAP1 mutant, V77E (called GCAP1 ${ }^{\text {V77E }}$ ) was shown previously to abolish dimerization of GCAP1 that significantly sharpened its NMR spec- 
trum, and GCAP1 $1^{\mathrm{V77E}}$ was used to solve the NMR structure of $\mathrm{Ca}^{2+}$-free $/ \mathrm{Mg}^{2+}$-bound GCAP1 ${ }^{\mathrm{V} 77 \mathrm{E}}$ [48]. The NMR structure of $\mathrm{Ca}^{2+}$-free $/ \mathrm{Mg}^{2+}$-bound GCAP1 ${ }^{\mathrm{V77E}}$ is shown in Figure 2C. The overall structure of $\mathrm{Ca}^{2+}$-free $/ \mathrm{Mg}^{2+}$-bound GCAP1 ${ }^{\mathrm{V} 77 \mathrm{E}}$ is similar to the crystal structure of $\mathrm{Ca}^{2+}$-bound GCAP1 (root mean squared deviation of main-chain atoms is $2.4 \AA$ when comparing the two structures). The overall structural similarity between $\mathrm{Ca}^{2+}$-free and $\mathrm{Ca}^{2+}$-bound GCAP1 may explain why GCAP1 has nearly a 100-fold higher $\mathrm{Ca}^{2+}$-binding affinity compared to the $\mathrm{Ca}^{2+}$ sensor proteins like recoverin and calmodulin that undergo large and unfavorable conformational changes coupled to $\mathrm{Ca}^{2+}$ binding $[49,57]$. In a sense, the GCAP proteins are more like the $\mathrm{Ca}^{2+}$ buffer proteins (calbindins and parvalbumin) that adopt pre-formed EF-hand open structures in the absence of $\mathrm{Ca}^{2+}$, which allows the buffer proteins to have maximal $\mathrm{Ca}^{2+}$ binding affinity [57]. However, small $\mathrm{Ca}^{2+}$-dependent structural changes are detected within the EF-hands: $\mathrm{Ca}^{2+}$ binding to EF2 reveals a small change in the helix packing angle (Figure $3 \mathrm{~A}$ ). The interhelical angle of the $\mathrm{Mg}^{2+}$-bound EF2 $\left(114^{\circ}\right.$, highlighted red in Figure 3A) is slightly more closed than the interhelical angle of $\mathrm{Ca}^{2+}$-bound EF2 $\left(110^{\circ}\right.$, highlighted cyan in Figure 3A). A similar $\mathrm{Ca}^{2+}$-induced opening of the interhelical angle is also apparent in EF3 (Figure 3B). Thus, the small $\mathrm{Ca}^{2+}$-dependent conformational changes in EF2 and EF3 might be functionally important for regulating RetGC. The largest $\mathrm{Ca}^{2+}$-induced structural change in GCAP1 is observed in the $\mathrm{Ca}^{2+}$ switch helix (residues 169-174 highlighted red in Figure 3C,D). Residues in the $\mathrm{Ca}^{2+}$ switch helix (T171 and L174) exhibit $\mathrm{Ca}^{2+}$-dependent solvent accessibility. T171 is exposed in the $\mathrm{Ca}^{2+}$-free structure, whereas it becomes buried and makes contact with L92 in the $\mathrm{Ca}^{2+}$-bound structure. Conversely, L174 is buried and makes contact with $\mathrm{L} 92$ in the $\mathrm{Ca}^{2+}$-free structure, in contrast to its solvent-exposed environment in the $\mathrm{Ca}^{2+}$-bound structure. These $\mathrm{Ca}^{2+}$-dependent contacts to the $\mathrm{Ca}^{2+}$ switch helix may be important for switching GCAP1 from the $\mathrm{Ca}^{2+}$-free activator to the $\mathrm{Ca}^{2+}$-bound inhibitor states. The $\mathrm{Ca}^{2+}$-induced shortening of the $\mathrm{Ca}^{2+}$ switch helix may also serve a role in modulating $\mathrm{Ca}^{2+}$-dependent contacts with RetGC.

A

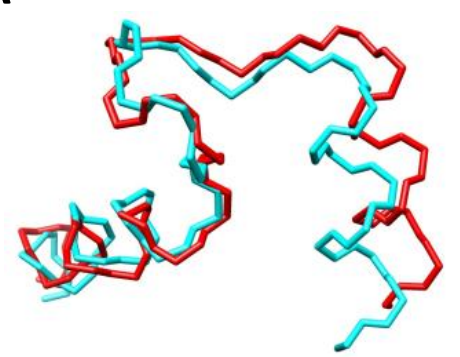

C

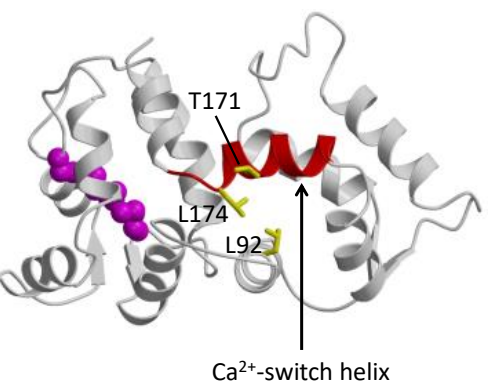

B

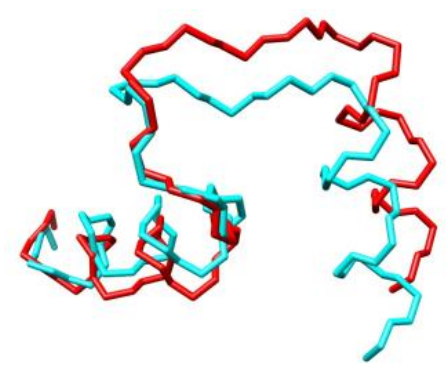

D

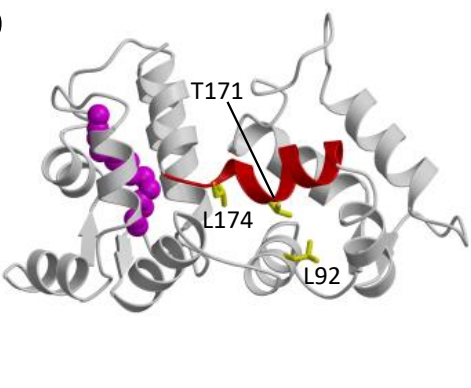

Figure 3. $\mathrm{Ca}^{2+}$-induced conformational changes in GCAP1. Main chain structures of EF2 (A), EF3 (B), $\mathrm{Mg}^{2+}$-bound $/ \mathrm{Ca}^{2+}$-free GCAP1 ${ }^{\mathrm{V} 77 \mathrm{E}}(\mathrm{C})$, and $\mathrm{Ca}^{2+}$-bound GCAP1 (D). The $\mathrm{Ca}^{2+}$-free structures of EF2 and EF3 (red in panels $(\mathbf{A}, \mathbf{B})$ ) are overlaid on top of the $\mathrm{Ca}^{2+}$-bound structures (cyan). EF2 and EF3 exhibit a $\mathrm{Ca}^{2+}$-induced decrease in interhelical angle. The $\mathrm{Ca}^{2+}$-switch helix (residues 169-174) undergoes a $\mathrm{Ca}^{2+}$-induced shortening (highlighted red in panels $(\mathbf{C}, \mathbf{D})$ ). 


\subsection{Dimeric Structures of GCAP1 and GCAP2}

The GCAP proteins have a propensity to self-associate as dimers at protein concentrations in the micromolar range or higher [48,60-62]. The relatively high dissociation constant of GCAP dimerization may shift into the physiological range if a pre-formed GCAP dimer binds with nanomolar affinity to a RetGC dimer [63] to form a 2:2 complex $\left(\mathrm{GCAP}_{2} / \mathrm{RetGC}_{2}\right)$ [64]. In essence, the high-affinity binding of GCAP1 to RetGC should shift the apparent dissociation constant of the GCAP1 dimer (bound to RetGC) into the sub-micromolar range. $\mathrm{Ca}^{2+}$-induced structural changes to the quaternary structure of a $\mathrm{GCAP}_{2} / \operatorname{RetGC}_{2}$ complex (Figure 4 ) are proposed here to amplify the relatively small $\mathrm{Ca}^{2+}$ induced change in the GCAP1 tertiary structure (Figure 3). Indeed, the binding of $\mathrm{Ca}^{2+}$ to GCAP1 was shown previously to cause a 6 -fold decrease in the dissociation constant for GCAP1 dimerization [61]. Missense mutations affecting $\mathrm{Ca}^{2+}$ binding to GCAP1 also lead to cone-rod dystrophies by altering protein dimerization and functional properties [65]. Thus, $\mathrm{Ca}^{2+}$-dependent quaternary structural changes in the $\mathrm{GCAP}_{2} / \mathrm{RetGC}_{2}$ complex may allosterically regulate the RetGC cyclase activity (Figure 4), similar to the allosteric regulation of $\mathrm{O}_{2}$ binding to hemoglobin [66]. Recall for hemoglobin, the $\mathrm{O}_{2}$-induced change in the tertiary structure of hemoglobin is quite small, but $\mathrm{O}_{2}$ binding causes a much larger change in the quaternary structure of the hemoglobin tetramer, known as the $\mathrm{T} \rightarrow \mathrm{R}$ transition. A similar allosteric transition may take place in the $\mathrm{GCAP}_{2} / \operatorname{RetGC}_{2}$ complex (Figure 4) and therefore explain how $\mathrm{Ca}^{2+}$ binding can modulate cyclase activity with positive cooperativity [8,14]. Atomic-level structures of dimeric forms of GCAP1 [67] and GCAP2 [68] have been reported and were described in a recent review [69]. I will provide an updated overview of the dimeric GCAP structures below.

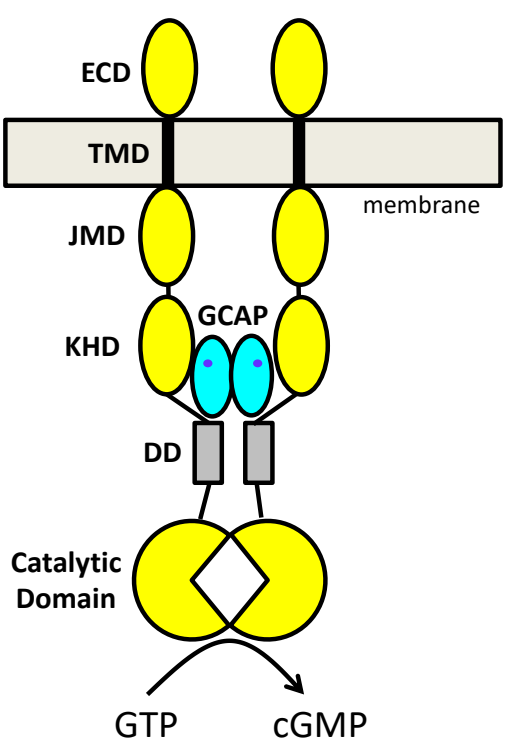

$$
\begin{aligned}
& \text { Active GCAP } / \text { RetGC }_{2} \\
& \text { (Low } \mathrm{Ca}^{2+} / \mathrm{T} \text { state) }
\end{aligned}
$$

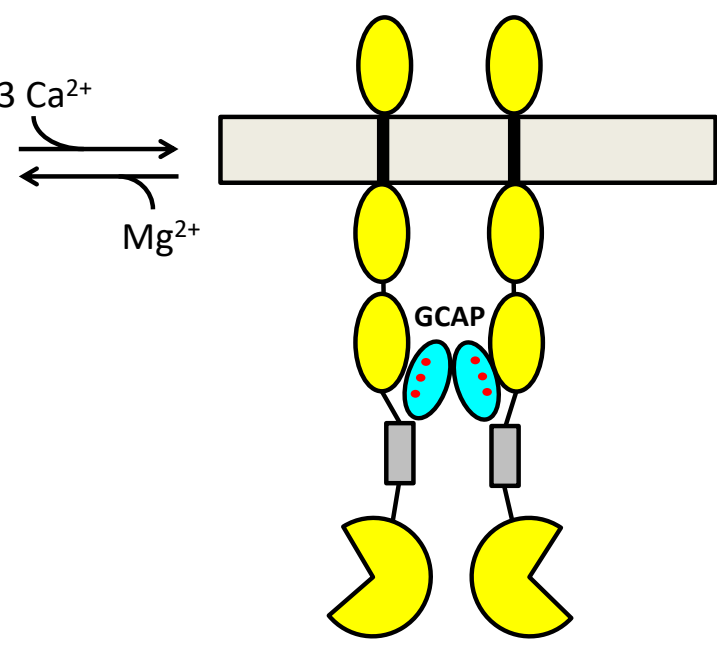

Inactive $\mathrm{GCAP}_{2} /$ RetGC $_{2}$
(High $\mathrm{Ca}^{2+} / \mathrm{R}_{\text {state) }}$

Figure 4. Allosteric regulation of a $\mathrm{GCAP}_{2} / \operatorname{RetGC}_{2}$ complex. Cyclase activity (synthesis of cGMP) is modulated by a $\mathrm{Ca}^{2+}$-dependent change in the quaternary structure of the $\mathrm{GCAP}_{2} / \operatorname{RetGC}_{2}$ complex. The $\mathrm{Ca}^{2+}-$ free $/ \mathrm{Mg}^{2+}$-bound GCAP1 dimer (cyan ovals with bound $\mathrm{Mg}^{2+}$ in blue) binds to the RetGC dimer (yellow) and activates cyclase activity (left panel). The $\mathrm{Ca}^{2+}$ - bound GCAP1 dimer (cyan ovals with three bound $\mathrm{Ca}^{2+}$ in red) binds to the RetGC dimer (yellow) and inactivates cyclase activity (right panel). Thus, the binding of $3 \mathrm{Ca}^{2+}$ to the GCAPs promotes the $\mathrm{T} \rightarrow \mathrm{R}$ transition (turns off cyclase activity), whereas the dissociation of $\mathrm{Ca}^{2+}$ and binding of $\mathrm{Mg}^{2+}$ promotes the $\mathrm{R} \rightarrow \mathrm{T}$ transition (turns on cyclase activity). Each RetGC dimer subunit is composed of an extracellular domain (ECD), transmembrane domain (TMD in black), juxtamembrane domain (JMD), kinase homology domain (KHD), dimerization domain (DD, gray), and catalytic cyclase domain (notched circles). 
The atomic-level structure of a GCAP1 dimer (Figure 5A) was modeled previously by a molecular docking approach that used intermolecular distance restraints experimentally measured by EPR-DEER [67] and a separate dimerization model was calculated from small X-ray scattering (SAXS) measurements [61]. The GCAP1 dimer is comprised of mostly hydrophobic intermolecular contacts at the dimer interface (Figure 5B). The most apparent intermolecular contacts involve exposed hydrophobic residues: H19, Y22, M26, V77, and W94 (Figure 5B). A key linchpin contact is formed by the methyl side-chain atoms of V77 that each contact one another at the dimer interface and perhaps explain why the V77E mutation disrupts GCAP1 dimerization [48]. The GCAP1 dimerization site is further stabilized by intermolecular contacts formed by exposed aromatic side chains of H19, Y22, F73, and W94. The point mutation p.H19Y in human GCAP1 that is located in the dimer interface was identified in patients diagnosed with retinitis pigmentosa, and the H19Y GCAP1 mutant protein disrupts RetGC regulation and dimer formation [61,70]. Single point mutations of the hydrophobic residues at the GCAP1 dimer interface (H19A, Y22A, F73A, V77E, and W94A) also each weaken the dimerization dissociation constant and abolish the activation of RetGC by GCAP1 [67]. Thus, the hydrophobic contacts at the GCAP1 dimer interface (Figure 5B) are essential for both its dimerization and activation of RetGCs. This implies that GCAP1 dimerization may be important for activating RetGC and therefore supports the idea of a pre-formed GCAP1 dimer that binds to the dimeric RetGC to stabilize a high affinity 2:2 target complex as discussed above (Figures 4 and 6B). Alternatively, the pre-formed GCAP1 dimer in solution may not exist in the presence of RetGC, because residues in the GCAP1 dimer interface (Figure 5B) appear to overlap with residues that interact with RetGC [71]. Thus, the residues at the GCAP1 dimerization site may prefer to interact with RetGC in the presence of saturating RetGC (Figure 6B), and the binding of RetGC to GCAP1, in this case, would be expected to prevent GCAP1 dimerization. Future studies are needed to probe whether the structure of the GCAP1 dimer (Figure 5A) will remain intact upon its binding to RetGC. In particular, future cryoEM studies are needed to determine the atomic-level structure of RetGC bound to GCAP1.
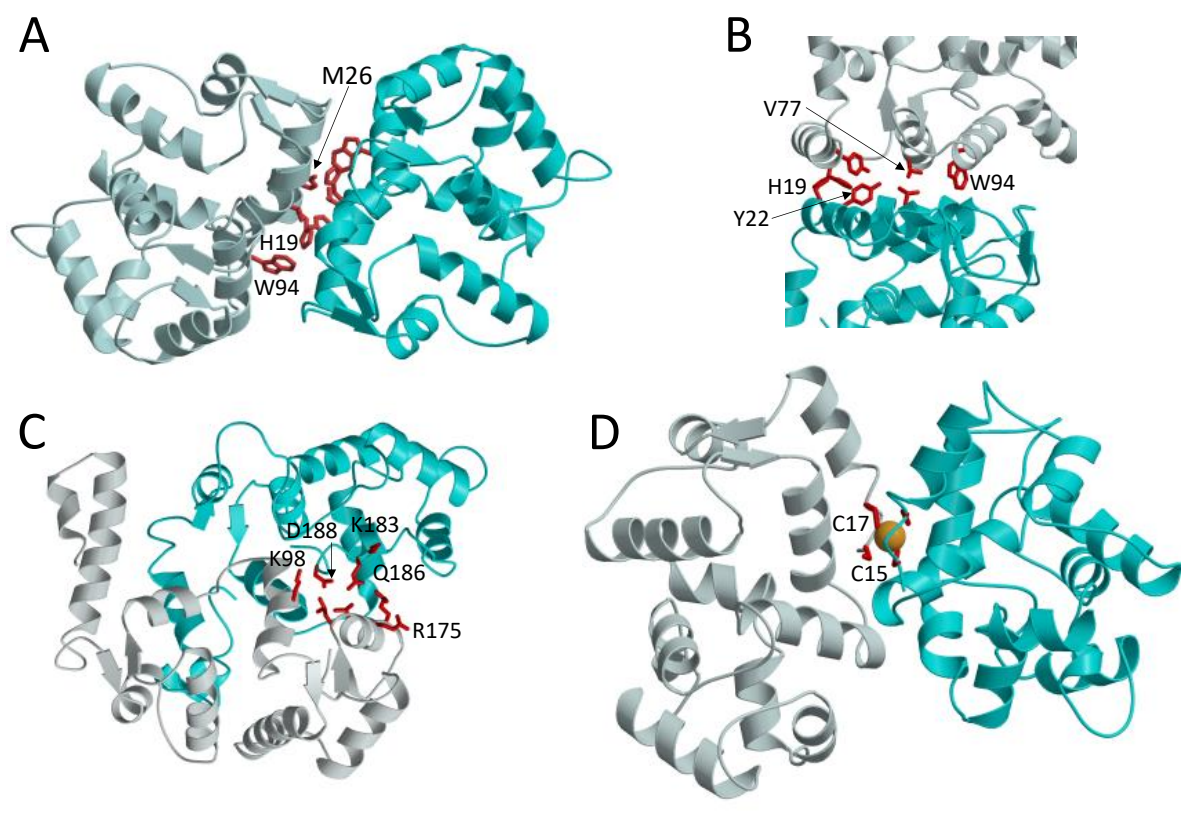

Figure 5. Dimeric structures of GCAP1 (A), GCAP2 (C), and GCAP5 (D). A close-up view of the GCAP1 dimerization site (B) reveals intermolecular contacts between aromatic residues (red). The GCAP2 dimerization site is stabilized by intermolecular salt bridges and hydrogen bonds (highlighted by red residues in panel (C)). The GCAP5 dimerization site is stabilized by a bound $\mathrm{Fe}^{2+}$ (orange sphere) that is chelated by C15 and C17 (D). 

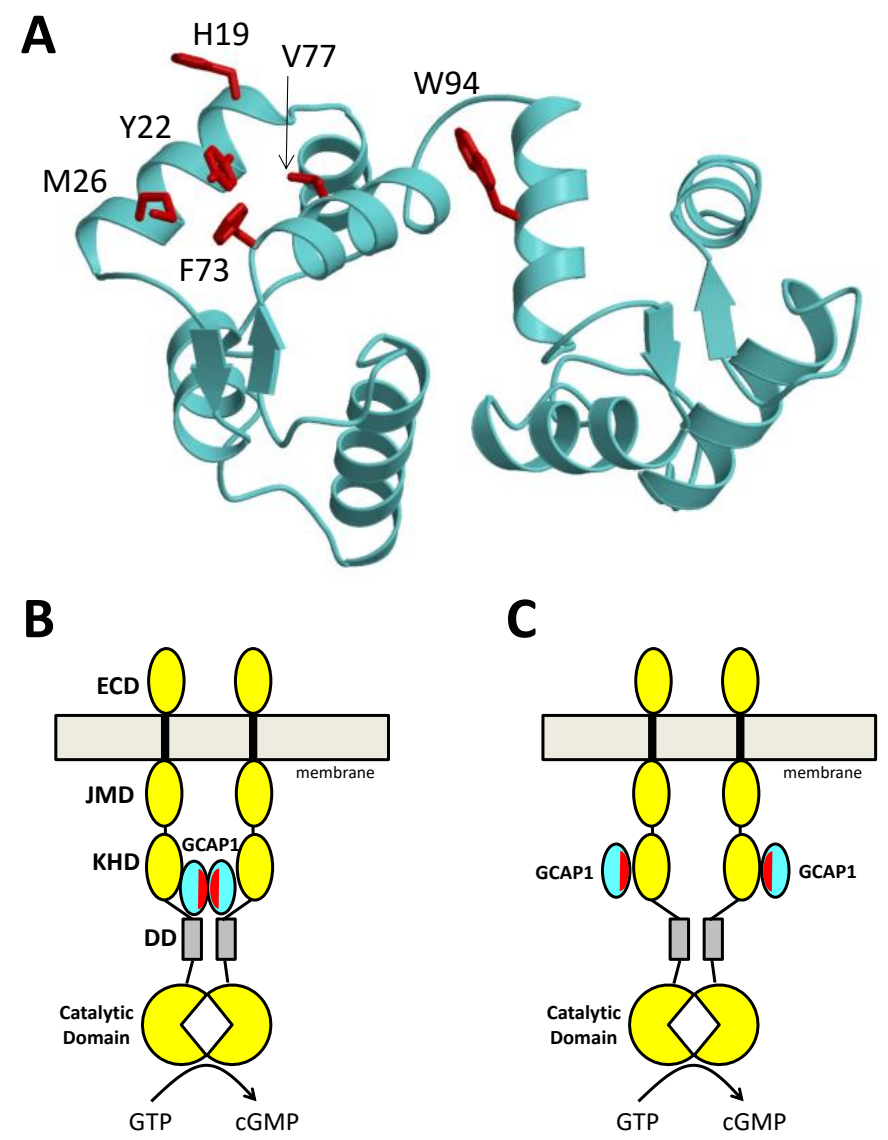

Figure 6. Druggable Hotspot on GCAP1 (A) and RetGC activation by dimeric (B) or monomeric (C) GCAPs. The structure of GCAP1 (cyan) contains exposed hotspot residues (red) that can mediate GCAP dimerization (B) or RetGC binding (C). RetGC (yellow) is proposed here to be activated by either a preformed GCAP1 dimer (B) or by monomeric GCAP1 (C). Small molecule drugs or peptides that bind to the hotspot are expected to prevent cyclase activation by constitutively active GCAP1 mutants and therefore may serve as therapeutics for cone-rod dystrophies. Each RetGC dimer subunit (yellow) is composed of an extracellular domain (ECD), transmembrane domain (black), juxtamembrane domain (JMD), kinase homology domain (KHD), dimerization domain (gray), and catalytic cyclase domain.

A structure of the GCAP2 dimer (Figure 5C) was reported previously based on a mass spectrometry analysis [68,72]. The overall quaternary structure of the GCAP2 dimer (Figure 5C) is very different from that of GCAP1 (Figure 5A). In contrast to the dimerization site in GCAP1, the GCAP2 dimerization site is comprised of mostly polar and charged amino acid residues (K98, L167, V171, R175, K183, Q186, D188 highlighted red in Figure 5C). The GCAP2 interface is therefore stabilized primarily by intermolecular salt bridges and hydrogen bonds. The side-chain atoms of R175 in GCAP2 form intermolecular hydrogen bonds with the polar side-chain atoms of Q186 (Figure 5C), and the side-chain atoms of K98 form an intermolecular salt bridge with the side chain carboxylate atoms of D188 (Figure 5C). These intermolecular polar contacts in the GCAP2 dimer are not conserved in the other GCAPs and may explain why the GCAP2 dimer structure (Figure 5C) is quite different from that of GCAP1 (Figure 5A). The different quaternary structures for the GCAP1 and GCAP2 dimers might help to understand their different targeting of RetGC $[73,74]$. GCAP1 has been shown previously to bind to the kinase homology domain in RetGC $[74,75]$, in contrast to GCAP2 that has been suggested to bind to RetGC residues (Y1016-S1103) at the C-terminus [73]. 


\subsection{GCAP5 Is a Fe ${ }^{2+}$ Sensor in Zebrafish Photoreceptors}

GCAP homologs are conserved in all vertebrate photoreceptors, and zebrafish photoreceptors contain particular GCAP homologs (GCAP3-5 in Figure 1) [16,76] that do not exist in mammals. The zebrafish homolog called GCAP5 has an amino acid sequence that is perhaps the most divergent of all GCAPs (Figure 1). The first 20 amino acids from the amino-terminus in GCAP5 are particularly unique and contain non-conserved Cys residues (Cys15 and Cys17) that were shown previously to bind $\mathrm{Fe}^{2+}[62]$. One $\mathrm{Fe}^{2+}$ binds with nanomolar affinity to two molecules of GCAP5 at the dimer interface and at least two other $\mathrm{Fe}^{2+}$ molecules bind to GCAP5 with a dissociation constant in the micromolar range [62]. The nanomolar $\mathrm{Fe}^{2+}$ binding to GCAP5 is abolished by the GCAP5 mutations (C15A and C17A), implying that the high-affinity $\mathrm{Fe}^{2+}$ is chelated by the sulfhydryl side chains of Cys15 and Cys17. By contrast, the lower affinity $\mathrm{Fe}^{2+}$ binding was not affected by the Cys mutations (C15A and C17A). A detailed NMR titration revealed that the lower affinity $\mathrm{Fe}^{2+}$ ions are likely binding to the second and third EF-hands in the absence of $\mathrm{Ca}^{2+}$ because the micromolar $\mathrm{Fe}^{2+}$ binding is abolished in the presence of saturating $\mathrm{Ca}^{2+}$ levels. The $\mathrm{Ca}^{2+}$-free $/ \mathrm{Fe}^{2+}$-free $/ \mathrm{Mg}^{2+}$-bound GCAP5 causes $~ 10$-fold activation of RetGC activity, which is somewhat lower than the cyclase activation promoted by $\mathrm{Ca}^{2+}-$ free $/ \mathrm{Mg}^{2+}$-bound GCAP1 [62]. Unlike GCAP1 and GCAP2, both the $\mathrm{Ca}^{2+}$-free and $\mathrm{Ca}^{2+}$-bound forms of GCAP5 can each activate RetGC. Interestingly, the $\mathrm{Fe}^{2+}$-bound GCAP5 is unable to activate RetGC even at low $\mathrm{Ca}^{2+}$ levels in light-adapted photoreceptors. The $\mathrm{Fe}^{2+}$-induced cyclase inhibition by GCAP5 suggests that $\mathrm{Fe}^{2+}$ binding to GCAP5 may serve to modulate cyclase activity and therefore GCAP5 could act as a $\mathrm{Fe}^{2+}$ sensor for phototransduction in zebrafish photoreceptors [62].

A structural model of $\mathrm{Fe}^{2+}$-bound GCAP5 was determined by an NMR-guided homology modeling approach [62] (Figure 5D). GCAP5 was measured by size-exclusion chromatography to form a protein dimer at micromolar protein concentrations [62] and was accordingly modeled to form a dimer in the structure. The GCAP5 dimer structure (Figure 5D) is somewhat similar to the structure of the GCAP1 dimer (Figure 5A). The GCAP5 dimerization site contains exposed hydrophobic residues (H18, Y21, M25, F72, V76, and W93) that are also present in the GCAP1 dimer (Figure 5B). A single $\mathrm{Fe}^{2+}$ is bound to the GCAP5 dimer in which the bound $\mathrm{Fe}^{2+}$ is chelated by the side chains of Cys15 and Cys17. The bound $\mathrm{Fe}^{2+}$ bridges two GCAP5 molecules into a [Fe(SCys) ${ }_{4}$ ] dimeric complex [62] like that observed previously in two-iron superoxide reductases [77,78]. The four cysteinyl thiolate groups that ligate the bound $\mathrm{Fe}^{2+}$ are similar in structure to the four Cys residues found in the $\mathrm{Cys}_{4}$ zinc finger motif that binds to $\mathrm{Zn}^{2+}$ [79]. The structural similarity to the $\mathrm{Cys}_{4}$ zinc finger suggests that GCAP5 may also bind to $\mathrm{Zn}^{2+}$ in place of $\mathrm{Fe}^{2+}$. High levels of $\mathrm{Zn}^{2+}$ are found in retinal photoreceptor cells, and $\mathrm{Zn}^{2+}$ may play a role in phototransduction [80]. Future studies are needed to test whether $\mathrm{Zn}^{2+}$ can bind to GCAP5 and test whether $\mathrm{Zn}^{2+}$ binding to GCAP5 can regulate RetGCs in zebrafish photoreceptors.

\subsection{Druggable Hot Spot on the Structure of GCAP1}

The structure of GCAP1 reveals exposed hydrophobic residues (H19, Y22, M26, F73, V77, and W94) that are clustered on the surface of the protein and form a potential hot spot for drug targeting (Figure 6A). These exposed hydrophobic residues are located at the GCAP1 dimerization site (Figure 5B), which explains why single mutations to these residues (H19A, Y22A, M26A, F73A, V77E, and W94E) both weaken dimerization and abolish cyclase activation [67]. A schematic model of a preformed GCAP1 dimer bound to RetGC suggests how GCAP1 dimerization might promote cyclase activation (Figure 6B). Alternatively, a monomeric form of GCAP1 bound to RetGC could also promote cyclase activation (Figure 6C), if the exposed hotspot on GCAP1 were to bind directly to RetGC as suggested by [71]. Regardless of whether the exposed hotspot facilitates GCAP1 dimerization (Figure 6B) or binds to RetGC (Figure 6C), this hotspot (highlighted red in Figure 6) could be targeted for drug design. Small molecules or peptides that bind specifically to the hotspot region are expected to block GCAP1 dimerization and/or RetGC binding and 
should therefore prevent cyclase activation by GCAP1. Small molecule inhibitors that bind to the hotspot region within constitutively active GCAP1 mutants (Y99C, D100G, E111V, and E155G) should block their activation of RetGCs, and therefore diminish the onset of cone-rod dystrophies. Future studies are needed to first screen for drug molecules that bind to the GCAP1 hot spot and then determine whether these drugs can serve as therapeutics for cone-rod dystrophies.

Funding: This research was funded by the National Eye Institute (R01 EY012347).

Institutional Review Board Statement: Not Applicable.

Informed Consent Statement: Not Applicable.

Data Availability Statement: Not Applicable.

Conflicts of Interest: The author declares no conflict of interest.

\section{References}

1. Stryer, L. Visual excitation and recovery. J. Biol. Chem. 1991, 266, 10711-10714. [CrossRef]

2. Baylor, D. How photons start vision. Proc. Natl. Acad. Sci. USA 1996, 93, 560-565. [CrossRef]

3. Pugh, E.N.; Duda, T.; Sitaramayya, A.; Sharma, R.K.; Pugh, J.E.N. Photoreceptor Guanylate Cyclases: A Review. Biosci. Rep. 1997, 17, 429-473. [CrossRef]

4. Pugh, E.; Nikonov, S.; Lamb, T. Molecular mechanisms of vertebrate photoreceptor light adaptation. Curr. Opin. Neurobiol. 1999, 9, 410-418. [CrossRef]

5. Burns, E.M.; A Baylor, D. Activation, Deactivation, and Adaptation in Vertebrate Photoreceptor Cells. Annu. Rev. Neurosci. 2001, 24, 779-805. [CrossRef]

6. Koch, K.-W.; Stryer, L. Highly cooperative feedback control of retinal rod guanylate cyclase by calcium ions. Nat. Cell Biol. 1988, 334, 64-66. [CrossRef]

7. Koutalos, Y.; Yau, K.W. Regulation of sensitivity in vertebrate rod photoreceptors by calcium. Trends Neurosci. 1996, 19 , 73-81. [CrossRef]

8. Dizhoor, A. The human photoreceptor membrane guanylyl cyclase, RetGC, is present in outer segments and is regulated by calcium and a soluble activator. Neuron 1994, 12, 1345-1352. [CrossRef]

9. Lowe, D.G.; Dizhoor, A.; Liu, K.; Gu, Q.; Spencer, M.; Laura, R.; Lu, L.; Hurley, J.B. Cloning and expression of a second photoreceptor-specific membrane retina guanylyl cyclase (RetGC), RetGC-2. Proc. Natl. Acad. Sci. USA 1995, 92, 5535-5539. [CrossRef]

10. Duda, T.; Fik-Rymarkiewicz, E.; Venkataraman, V.; Krishnan, R.; Koch, K.-W.; Sharma, R.K. The Calcium-Sensor Guanylate Cyclase Activating Protein Type 2 Specific Site in Rod Outer Segment Membrane Guanylate Cyclase Type 1. Biochemistry 2005, 44, 7336-7345. [CrossRef] [PubMed]

11. Laura, R.P.; Dizhoor, A.M.; Hurley, J.B. The membrane guanylyl cyclase, retinal guanylyl cyclase-1, is activated through its intracellular domain. J. Biol. Chem. 1996, 271, 11646-11651. [CrossRef]

12. Dizhoor, A.M.; Olshevskaya, E.V.; Henzel, W.; Wong, S.C.; Stults, J.T.; Ankoudinova, I.; Hurley, J.B. Cloning, Sequencing, and Expression of a 24-kDa Ca ${ }^{2+}$-binding Protein Activating Photoreceptor Guanylyl Cyclase. J. Biol. Chem. 1995, 270, 25200-25206. [CrossRef]

13. Gorczyca, W.; Polans, A.S.; Surgucheva, I.G.; Subbaraya, I.; Baehr, W.; Palczewski, K. Guanylyl cyclase activating protein. A calcium-sensitive regulator of phototransduction. J. Biol. Chem. 1995, 270, 22029-22036. [CrossRef]

14. Palczewski, K.; Subbaraya, I.; Gorczyca, W.A.; Helekar, B.S.; Ruiz, C.C.; Ohguro, H.; Huang, J.; Zhao, X.; Crabb, J.W.; Johnson, R.S.; et al. Molecular cloning and characterization of retinal photoreceptor guanylyl cyclase-activating protein. Neuron 1994, 13, 395-404. [CrossRef]

15. Scholten, A.; Koch, K.-W. Differential Calcium Signaling by Cone Specific Guanylate Cyclase-Activating Proteins from the Zebrafish Retina. PLoS ONE 2011, 6, e23117. [CrossRef]

16. Rätscho, N.; Scholten, A.; Koch, K.-W. Expression profiles of three novel sensory guanylate cyclases and guanylate cyclaseactivating proteins in the zebrafish retina. Biochim. Biophys. Acta (BBA) Bioenerg. 2009, 1793, 1110-1114. [CrossRef]

17. Gray-Keller, M.P.; Detwiler, P. The calcium feedback signal in the phototransduction cascade of vertebrate rods. Neuron 1994, 13, 849-861. [CrossRef]

18. Woodruff, M.L.; Sampath, A.P.; Matthews, H.R.; Krasnoperova, N.V.; Lem, J.; Fain, G.L. Measurement of cytoplasmic calcium concentration in the rods of wild-type and transducin knock-out mice. J. Physiol. 2002, 542, 843-854. [CrossRef] [PubMed]

19. Dizhoor, A.; Hurley, J.B. Inactivation of EF-hands Makes GCAP-2 (p24) a Constitutive Activator of Photoreceptor Guanylyl Cyclase by Preventing a Ca ${ }^{2+}$-induced “Activator-to-Inhibitor” Transition. J. Biol. Chem. 1996, 271, 19346-19350. [CrossRef] [PubMed] 
20. Méndez, A.; Burns, M.E.; Sokal, I.; Dizhoor, A.; Baehr, W.; Palczewski, K.; Baylor, D.A.; Chen, J. Role of guanylate cyclaseactivating proteins (GCAPs) in setting the flash sensitivity of rod photoreceptors. Proc. Natl. Acad. Sci. USA 2001, 98, $9948-9953$. [CrossRef]

21. Dizhoor, A.M.; Boikov, S.G.; Olshevskaya, E.V. Constitutive Activation of Photoreceptor Guanylate Cyclase by Y99C Mutant of GCAP-1. Possible role in causing human autosomal dominant cone degeneration. J. Biol. Chem. 1998, 273, 17311-17314. [CrossRef]

22. Hodgkin, A.L.; Nunn, B.J. Control of light-sensitive current in salamander rods. J. Physiol. 1988, 403, 439-471. [CrossRef]

23. Sakurai, K.; Chen, J.; Kefalov, V.J. Role of Guanylyl Cyclase Modulation in Mouse Cone Phototransduction. J. Neurosci. 2011, 31, 7991-8000. [CrossRef]

24. Dizhoor, A.M.; Olshevskaya, E.V.; Peshenko, I.V. $\mathrm{Mg}^{2+} / \mathrm{Ca}^{2+}$ cation binding cycle of guanylyl cyclase activating proteins (GCAPs): Role in regulation of photoreceptor guanylyl cyclase. Mol. Cell. Biochem. 2009, 334, 117-124. [CrossRef]

25. Peshenko, I.V.; Dizhoor, A.M. Guanylyl cyclase-activating proteins (GCAPs) are $\mathrm{Ca}^{2+} / \mathrm{Mg}^{2+}$ sensors: Implications for photoreceptor guanylyl cyclase (RetGC) regulation in mammalian photoreceptors. J. Biol. Chem. 2004, 279, 16903-16906. [CrossRef] [PubMed]

26. Peshenko, I.V.; Dizhoor, A.M. $\mathrm{Ca}^{2+}$ and $\mathrm{Mg}^{2+}$ binding properties of GCAP-1. Evidence that $\mathrm{Mg}^{2+}$-bound form is the physiological activator of photoreceptor guanylyl cyclase. J. Biol. Chem. 2006, 281, 23830-23841. [CrossRef]

27. Peshenko, I.V.; Dizhoor, A.M. Activation and Inhibition of Photoreceptor Guanylyl Cyclase by Guanylyl Cyclase Activating Protein 1 (GCAP-1): THE FUNCTIONAL ROLE OF $\mathrm{Mg}^{2+} / \mathrm{Ca}^{2+}$ EXCHANGE IN EF-HAND DOMAINS. J. Biol. Chem. 2007, 282, 21645-21652. [CrossRef]

28. Lim, S.; Peshenko, I.; Dizhoor, A.; Ames, J.B. Effects of $\mathrm{Ca}^{2+}, \mathrm{Mg}^{2+}$, and Myristoylation on Guanylyl Cyclase Activating Protein 1 Structure and Stability. Biochemistry 2009, 48, 850-862. [CrossRef]

29. Dell'Orco, D.; Behnen, P.; Linse, S.; Koch, K.-W. Calcium binding, structural stability and guanylate cyclase activation in GCAP1 variants associated with human cone dystrophy. Cell. Mol. Life Sci. 2010, 67, 973-984. [CrossRef] [PubMed]

30. Marino, V.; Sulmann, S.; Koch, K.-W.; Dell'Orco, D. Structural effects of $\mathrm{Mg}^{2+}$ on the regulatory states of three neuronal calcium sensors operating in vertebrate phototransduction. Biochim. Biophys. Acta (BBA) Bioenerg. 2015, 1853, 2055-2065. [CrossRef]

31. Ames, J.B.; Dizhoor, A.; Ikura, M.; Palczewski, K.; Stryer, L. Three-dimensional Structure of Guanylyl Cyclase Activating Protein-2, a Calcium-sensitive Modulator of Photoreceptor Guanylyl Cyclases. J. Biol. Chem. 1999, 274, 19329-19337. [CrossRef]

32. Stephen, R.; Bereta, G.; Golczak, M.; Palczewski, K.; Sousa, M.C. Stabilizing Function for Myristoyl Group Revealed by the Crystal Structure of a Neuronal Calcium Sensor, Guanylate Cyclase-Activating Protein 1. Structure 2007, 15, 1392-1402. [CrossRef]

33. Sampath, A.; Matthews, H.; Cornwall, M.; Fain, G. Bleached Pigment Produces a Maintained Decrease in Outer Segment Ca ${ }^{2+}$ in Salamander Rods. J. Gen. Physiol. 1998, 111, 53-64. [CrossRef] [PubMed]

34. Chen, C.; Nakatani, K.; Koutalos, Y. Free Magnesium Concentration in Salamander Photoreceptor Outer Segments. J. Physiol. 2003, 553, 125-135. [CrossRef]

35. Jiang, L.; Baehr, W. GCAP1 Mutations Associated with Autosomal Dominant Cone Dystrophy. Adv. Exp. Med. Biol. 2009, 664, 273-282. [CrossRef]

36. Behnen, P.; Dell'Orco, D.; Koch, K.-W. Involvement of the calcium sensor GCAP1 in hereditary cone dystrophies. Biol. Chem. 2010, 391, 631-637. [CrossRef] [PubMed]

37. Payne, A.; Downes, S.M.; Bessant, D.A.; Taylor, R.; Holder, G.E.; Warren, M.; Bird, A.C.; Bhattacharya, S.S. A mutation in guanylate cyclase activator 1A (GUCA1A) in an autosomal dominant cone dystrophy pedigree mapping to a new locus on chromosome 6p21.1. Hum. Mol. Genet. 1998, 7, 273-277. [CrossRef] [PubMed]

38. Nong, E.; Lee, W.; Merriam, J.E.; Allikmets, R.; Tsang, S.H. Disease progression in autosomal dominant cone-rod dystrophy caused by a novel mutation (D100G) in the GUCA1A gene. Doc. Ophthalmol. 2013, 128, 59-67. [CrossRef] [PubMed]

39. Marino, V.; Cortivo, G.D.; Oppici, E.; Maltese, P.E.; D’Esposito, F.; Manara, E.; Ziccardi, L.; Falsini, B.; Magli, A.; Bertelli, M.; et al. A novel p. (Glu111Val) missense mutation in GUCA1A associated with cone-rod dystrophy leads to impaired calcium sensing and perturbed second messenger homeostasis in photoreceptors. Hum. Mol. Genet. 2018, 27, 4204-4217. [CrossRef] [PubMed]

40. Wilkie, S.E.; Li, Y.; Deery, E.C.; Newbold, R.J.; Garibaldi, D.; Bateman, J.B.; Zhang, H.; Lin, W.; Zack, D.; Bhattacharya, S.S.; et al. Identification and Functional Consequences of a New Mutation (E155G) in the Gene for GCAP1 That Causes Autosomal Dominant Cone Dystrophy. Am. J. Hum. Genet. 2001, 69, 471-480. [CrossRef]

41. Wilkie, S.E.; Newbold, R.J.; Deery, E.; Walker, C.; Stinton, I.; Ramamurthy, V.; Hurley, J.B.; Bhattacharya, S.S.; Warren, M.J.; Hunt, D.M. Functional characterization of missense mutations at codon 838 in retinal guanylate cyclase correlates with disease severity in patients with autosomal dominant cone-rod dystrophy. Hum. Mol. Genet. 2000, 9, 3065-3073. [CrossRef] [PubMed]

42. Olshevskaya, E.V.; Calvert, P.D.; Woodruff, M.L.; Peshenko, I.V.; Savchenko, A.B.; Makino, C.L.; Ho, Y.-S.; Fain, G.L.; Dizhoor, A.M. The Y99C Mutation in Guanylyl Cyclase-Activating Protein 1 Increases Intracellular $\mathrm{Ca}^{2+}$ and Causes Photoreceptor Degeneration in Transgenic Mice. J. Neurosci. 2004, 24, 6078-6085. [CrossRef] [PubMed]

43. Sokal, I.; Li, N.; Surgucheva, I.; Warren, M.; Payne, A.; Bhattacharya, S.S.; Baehr, W.; Palczewski, K. GCAP1(Y99C) Mutant Is Constitutively Active in Autosomal Dominant Cone Dystrophy. Mol. Cell 1998, 2, 129-133. [CrossRef]

44. Olshevskaya, E.V.; Peshenko, I.V.; Savchenko, A.B.; Dizhoor, A.M. Retinal Guanylyl Cyclase Isozyme 1 Is the Preferential In Vivo Target for Constitutively Active GCAP1 Mutants Causing Congenital Degeneration of Photoreceptors. J. Neurosci. 2012, 32, 7208-7217. [CrossRef] [PubMed] 
45. Woodruff, M.L.; Olshevskaya, E.V.; Savchenko, A.B.; Peshenko, I.V.; Barrett, R.; Bush, R.A.; Sieving, P.A.; Fain, G.L.; Dizhoor, A.M. Constitutive Excitation by Gly90Asp Rhodopsin Rescues Rods from Degeneration Caused by Elevated Production of cGMP in the Dark. J. Neurosci. 2007, 27, 8805-8815. [CrossRef]

46. Peshenko, I.V.; Olshevskaya, E.V.; Dizhoor, A.M. Binding of guanylyl cyclase activating protein 1 (GCAP1) to retinal guanylyl cyclase (RetGC1): The role of individual EF-hands. J. Biol. Chem. 2008, 283, 21747-21757. [CrossRef]

47. Ermilov, A.N.; Olshevskaya, E.V.; Dizhoor, A. Instead of Binding Calcium, One of the EF-hand Structures in Guanylyl Cyclase Activating Protein-2 Is Required for Targeting Photoreceptor Guanylyl Cyclase. J. Biol. Chem. 2001, 276, 48143-48148. [CrossRef]

48. Lim, S.; Peshenko, I.V.; Olshevskaya, E.V.; Dizhoor, A.; Ames, J.B. Structure of Guanylyl Cyclase Activator Protein 1 (GCAP1) Mutant V77E in a $\mathrm{Ca}^{2+}$-free/ $\mathrm{Mg}^{2+}$-bound Activator State. J. Biol. Chem. 2016, 291, 4429-4441. [CrossRef]

49. Ames, J.B.; Ishima, R.; Tanaka, T.; Gordon, J.I.; Stryer, L.; Ikura, M. Molecular mechanics of calcium-myristoyl switches. Nat. Cell Biol. 1997, 389, 198-202. [CrossRef]

50. Flaherty, K.M.; Zozulya, S.; Stryer, L.; McKay, D.B. Three-dimensional structure of recoverin, a calcium sensor in vision. Cell 1993, 75, 709-716. [CrossRef]

51. Ames, J.B.; Porumb, T.; Tanaka, T.; Ikura, M.; Stryer, L. Amino-terminal Myristoylation Induces Cooperative Calcium Binding to Recoverin. J. Biol. Chem. 1995, 270, 4526-4533. [CrossRef]

52. Theisgen, S.; Scheidt, H.A.; Magalhães, A.; Bonagamba, T.J.; Huster, D. A solid-state NMR study of the structure and dynamics of the myristoylated N-terminus of the guanylate cyclase-activating protein-2. Biochim. Biophys. Acta (BBA) Biomembr. 2010, 1798, 266-274. [CrossRef]

53. Vogel, A.; Schröder, T.; Lange, C.; Huster, D. Characterization of the myristoyl lipid modification of membrane-bound GCAP-2 by 2H solid-state NMR spectroscopy. Biochim. Biophys. Acta (BBA) Biomembr. 2007, 1768, 3171-3181. [CrossRef]

54. Hwang, J.-Y.; Koch, K.-W. Calcium- and Myristoyl-Dependent Properties of Guanylate Cyclase-Activating Protein-1 and Protein-2. Biochemistry 2002, 41, 13021-13028. [CrossRef] [PubMed]

55. Margetić, A.; Nannemann, D.; Meiler, J.; Huster, D.; Theisgen, S. Guanylate Cyclase-Activating Protein-2 Undergoes Structural Changes upon Binding to Detergent Micelles and Bicelles. Biochim. Biophys. Acta (BBA) Biomembr. 2014, 1838, $2767-2777$. [CrossRef]

56. Olshevskaya, E.V.; Hughes, R.E.; Hurley, J.B.; Dizhoor, A. Calcium Binding, but Not a Calcium-Myristoyl Switch, Controls the Ability of Guanylyl Cyclase-activating Protein GCAP-2 to Regulate Photoreceptor Guanylyl Cyclase. J. Biol. Chem. 1997, 272, 14327-14333. [CrossRef] [PubMed]

57. Ikura, M. Calcium binding and conformational response in EF-hand proteins. Trends Biochem. Sci. 1996, 21, 14-17. [CrossRef]

58. Peshenko, I.V. Calcium-myristoyl Tug. J. Biol. Chem. 2012, 287, 13972-13984. [CrossRef]

59. Marino, V.; Dell'Orco, D. Allosteric communication pathways routed by $\mathrm{Ca}^{2+} / \mathrm{Mg}^{2+}$ exchange in GCAP1 selectively switch target regulation modes. Sci. Rep. 2016, 6, 34277. [CrossRef]

60. Lim, S.; Peshenko, I.V.; Dizhoor, A.; Ames, J.B. Structural Insights for Activation of Retinal Guanylate Cyclase by GCAP1. PLoS ONE 2013, 8, e81822. [CrossRef]

61. Bonì, F.; Marino, V.; Bidoia, C.; Mastrangelo, E.; Barbiroli, A.; Dell'Orco, D.; Milani, M. Modulation of Guanylate Cyclase Activating Protein 1 (GCAP1) Dimeric Assembly by $\mathrm{Ca}^{2+}$ or $\mathrm{Mg}^{2+}$ : Hints to Understand Protein Activity. Biomolecules 2020, 10, 1408. [CrossRef]

62. Lim, S.; Scholten, A.; Manchala, G.; Cudia, D.; Zlomke-Sell, S.-K.; Koch, K.-W.; Ames, J.B. Structural Characterization of Ferrous Ion Binding to Retinal Guanylate Cyclase Activator Protein 5 from Zebrafish Photoreceptors. Biochemistry 2017, 56, 6652-6661. [CrossRef] [PubMed]

63. Olshevskaya, E.V.; Ermilov, A.N.; Dizhoor, A. Dimerization of Guanylyl Cyclase-activating Protein and a Mechanism of Photoreceptor Guanylyl Cyclase Activation. J. Biol. Chem. 1999, 274, 25583-25587. [CrossRef]

64. Peshenko, I.V.; Olshevskaya, E.V.; Yao, S.; Ezzeldin, H.H.; Pittler, S.; Dizhoor, A.M. Activation of Retinal Guanylyl Cyclase RetGC1 by GCAP1: Stoichiometry of Binding and Effect of New LCA-Related Mutations. Biochemistry 2010, 49, 709-717. [CrossRef] [PubMed]

65. Cortivo, G.D.; Marino, V.; Bonì, F.; Milani, M.; Dell'Orco, D. Missense mutations affecting Ca ${ }^{2+}$-coordination in GCAP1 lead to cone-rod dystrophies by altering protein structural and functional properties. Biochim. Biophys. Acta (BBA) Bioenerg. 2020, 1867, 118794. [CrossRef]

66. Monod, J.; Wyman, J.; Changeux, J.-P. On the nature of allosteric transitions: A plausible model. J. Mol. Biol. 1965, 12, 88-118. [CrossRef]

67. Lim, S.; Roseman, G.; Peshenko, I.; Manchala, G.; Cudia, D.; Dizhoor, A.; Millhauser, G.; Ames, J.B. Retinal guanylyl cyclase activating protein 1 forms a functional dimer. PLOS ONE 2018, 13, e0193947. [CrossRef]

68. Pettelkau, J.; Schröder, T.; Ihling, C.H.; Olausson, B.E.S.; Kölbel, K.; Lange, C.; Sinz, A. Structural Insights into Retinal Guanylylcyclase-GCAP-2 Interaction Determined by Cross-Linking and Mass Spectrometry. Biochemistry 2012, 51, $4932-4949$. [CrossRef]

69. Ames, J.B. Dimerization of Neuronal Calcium Sensor Proteins. Front. Mol. Neurosci. 2018, 11, 397. [CrossRef]

70. Abbas, S.; Marino, V.; Weisschuh, N.; Kieninger, S.; Solaki, M.; Dell'Orco, D.; Koch, K.-W. Neuronal Calcium Sensor GCAP1 Encoded by GUCA1A Exhibits Heterogeneous Functional Properties in Two Cases of Retinitis Pigmentosa. ACS Chem. Neurosci. 2020, 11, 1458-1470. [CrossRef] 
71. Peshenko, I.V.; Olshevskaya, E.V.; Lim, S.; Ames, J.B.; Dizhoor, A.M. Identification of Target Binding Site in Photoreceptor Guanylyl Cyclase-activating Protein 1 (GCAP1). J. Biol. Chem. 2014, 289, 10140-10154. [CrossRef]

72. Pettelkau, J.; Thondorf, I.; Theisgen, S.; Lilie, H.; Schröder, T.; Arlt, C.; Ihling, C.H.; Sinz, A. Structural Analysis of Guanylyl Cyclase-Activating Protein-2 (GCAP-2) Homodimer by Stable Isotope-Labeling, Chemical Cross-Linking, and Mass Spectrometry. J. Am. Soc. Mass Spectrom. 2013, 24, 1969-1979. [CrossRef]

73. Duda, T.; Pertzev, A.; Sharma, R.K. Differential Ca ${ }^{2+}$ Sensor Guanylate Cyclase Activating Protein Modes of Photoreceptor Rod Outer Segment Membrane Guanylate Cyclase Signaling. Biochemistry 2012, 51, 4650-4657. [CrossRef]

74. Peshenko, I.V.; Olshevskaya, E.V.; Dizhoor, A.M. Evaluating the Role of Retinal Membrane Guanylyl Cyclase 1 (RetGC1) Domains in Binding Guanylyl Cyclase-activating Proteins (GCAPs). J. Biol. Chem. 2015, 290, 6913-6924. [CrossRef]

75. Laura, R.P.; Hurley, J.B. The Kinase Homology Domain of Retinal Guanylyl Cyclases 1 and 2 Specifies the Affinity and Cooperativity of Interaction with Guanylyl Cyclase Activating Protein-2. Biochemistry 1998, 37, 11264-11271. [CrossRef] [PubMed]

76. Imanishi, Y.; Yang, L.; Sokal, I.; Filipek, S.; Palczewski, K.; Baehr, W. Diversity of Guanylate Cyclase-Activating Proteins (GCAPs) in Teleost Fish: Characterization of Three Novel GCAPs (GCAP4, GCAP5, GCAP7) from Zebrafish (Danio rerio) and Prediction of Eight GCAPs (GCAP1-8) in Pufferfish (Fugu rubripes). J. Mol. Evol. 2004, 59, 204-217. [CrossRef]

77. Demaré, F.; Kurtz, D.M.; Nordlund, P. The structure of Desulfovibrio vulgaris rubrerythrin reveals a unique combination of rubredoxin-like FeS4 and ferritin-like diiron domains. Nat. Struct. Mol. Biol. 1996, 3, 539-546. [CrossRef] [PubMed]

78. Emerson, J.; Cabelli, D.E.; Kurtz, D.M. An engineered two-iron superoxide reductase lacking the [Fe(SCys)4] site retains its catalytic properties in vitro and in vivo. Proc. Natl. Acad. Sci. USA 2003, 100, 3802-3807. [CrossRef] [PubMed]

79. Tang, Q.; Liu, Y.-P.; Yan, X.-X.; Liang, D.-C. Structural and functional characterization of Cys4 zinc finger motif in the recombination mediator protein RecR. DNA Repair 2014, 24, 10-14. [CrossRef]

80. Redenti, S.; Ripps, H.; Chappell, R.L. Zinc release at the synaptic terminals of rod photoreceptors. Exp. Eye Res. 2007, 85, 580-584. [CrossRef] 